\title{
EXPERIMENTAL DESIGN APPLIED TO MODELING OF THE AIR-TIGHTNESS OF A BUILDING
}

\author{
Ivana Miličević \\ Josip Juraj Strossmayer University of Osijek, Faculty of Civil Engineering Osijek, Ph.D. \\ Corresponding author: ivana.milicevic@gfos.hr \\ Irena Ištoka Otković \\ Josip Juraj Strossmayer University of Osijek, Faculty of Civil Engineering Osijek, Assistant Professor \\ Željko Koški \\ Josip Juraj Strossmayer University of Osijek, Faculty of Civil Engineering Osijek, Associate Professor
}

\begin{abstract}
The paper presents experimental designs that can be used in modeling of the air-tightness of buildings as second-order functions using response surface method and corresponding experiment designs. The factors supposed to be significant for a model of building air-tightness - and thus those used in experiment designs-are the heat transfer coefficient for external walls, the heat transfer coefficient of the windows, and the position of the housing units with respect to the building envelope. We compared three-level full factorial and fractional factorial designs, as well as central composite designs and the Box-Behnken design.
\end{abstract}

Keywords: air-tightness, design of experiment, factorial designs, central composite designs, Box-Behnken design

\section{VRSTE PLANOVA EKSPERIMENTA ZA MODELIRANJE ZRAKOPROPUSNOSTI ZGRADA}

Sažetak: U radu su prikazane vrste planova eksperimenta koje se mogu koristiti za modeliranje zrakopropusnosti zgrada, a definirane su preko funkcije drugog reda pomoću metode odzivne površine i odgovarajućeg plana eksperimenta. Faktori koji bi trebali biti važni za model zrakopropusnosti zgrade te stoga upotrijebljeni u planu eksperimenta, su koeficijent prolaska topline za vanjske zidove, koeficijent prolaska topline za prozore i položaj stambenih jedinica u odnosu na ovojnicu zgrade. Uspoređeni su potpuni faktorski plan i djelomični faktorski plan na tri razine, te centralno kompozitni i Box-Behnkenov plan eksperimenta.

Ključne riječi: zrakopropusnost, plan eksperimenta, faktorski plan, centralno kompozitni plan, Box-Behnkenov plan 


\section{INTRODUCTION}

Experiments can be complicated when many variables can change the results. Thus, it is important to plan the experiment to capture the most important variables in a simple procedure without significantly reducing the accuracy of the results. In essence, it is ideal to perform the fewest possible experiments to obtain the most possible information that could be used to model the observed experimental process [1, 2].

In our case, the experimental plan used to determine the number of experiments needed to obtain a mathematical model is:

$$
y=f\left(x_{1}, x_{2}, x_{3}, \ldots x_{i}\right)
$$

where response $y$ is the air-tightness of a building, and factor values $x$ are the heat transfer coefficient for the external walls, the heat transfer coefficient of the windows, and the position of housing units with respect to the building envelope [3].

\section{EXPERIMENTAL DESIGN}

Experiment designs are needed so that the experiments are defined in an organized manner and allow statistical analysis to be performed on data, as shown in various areas of engineering [4-6]. In this paper, we will evaluate a second-order model of building air-tightness.

\subsection{Response surface methodology}

The response surface methodology (RSM) comprises methods that allow one to determine the equations that model how a response depends on various factors. RSM requires two factors $\left(x_{1}\right.$ and $\left.x_{2}\right)$ and one response $(y)$ :

$$
y=f\left(x_{1}, x_{2}\right)+\varepsilon
$$

where $f\left(x_{1} x_{2}\right)$ is the response model, and $\varepsilon$ is the model error compared to the real response $y$.

The response surface method is presented graphically over the whole design space of factor values. For instance, Figure 1 shows a response for two factors, each with ten values.

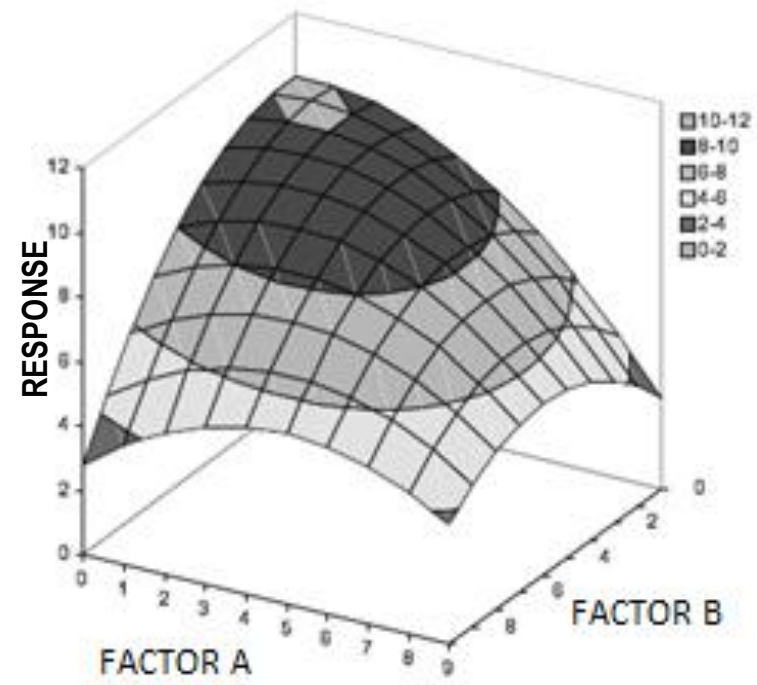

a)

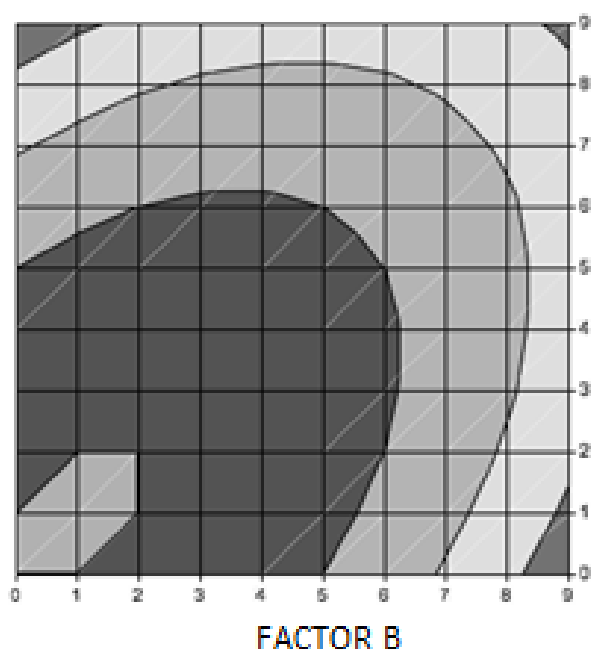

b)

Figure 1 Example of response surface: a) Three-dimensional plot of response surface b) Contour plot of response surface [7] 
We wish to determine the response model $f$. Thus, if a first-order model with $k$ factors

$$
y=f\left(x_{1}, x_{2}, \ldots, x_{k}\right)+\varepsilon=\beta_{0}+\beta_{1} x_{1}+\beta_{2} x_{2}+\cdots+\beta_{k} x_{k}+\varepsilon
$$

causes significant error $\varepsilon$ within the design space, we must introduce a model of higher order, e.g., a secondorder model:

$$
y=f\left(x_{1}, x_{2}, \ldots, x_{k}\right)+\varepsilon=\beta_{0}+\sum_{i=1}^{k} \beta_{i} x_{i}+\sum_{i=1}^{k} \beta_{i i} x_{i}^{2}+\sum_{i<j} \sum_{j=2} \beta_{i j} x_{i} x_{j}+\varepsilon
$$

where $y$ is the response, $x_{i}$ are the factors, and the coefficients $\beta$ must be calculated in order to minimize the error $\varepsilon$ within the design space. The coefficients are determined using the experimental response $y$, obtained by using at least three value levels of each factor. Two-level experiments only allow for the fitting of first-order models (3) with or without interaction terms and cannot detect curvature [1]. In the present work, we believe that the correlation between building air-tightness and the chosen factors can be described as a second-order polynomial function.

To minimize the number of experiments, it is recommended to apply an experimental design. In our case, we use an experimental design to define the minimum number of experiments needed to obtain a second-order model of building air-tightness (4). We will consider three-level full factorial and fractional factorial designs, as well as central composite designs and a Box-Behnken design [2]. We then compare the designs for their experimental feasibility based on cost and time constraints.

\subsection{Types of Factorial Design}

A full factorial design (full FD) is the most complete design for a particular number of factor levels. However, it demands many experiments:

$$
\text { number of experiments }=n^{k}
$$

where $k$ is the number of factors, and $n$ is the number of factor levels. If a full set of experiments cannot be performed because of cost, time, or other constraints, a fractional factorial design could be used.

A fractional factorial design (fractional FD) assumes that some effects are confounded with one another [1]. Thus, an effect is defined as a change in the average response between two factor-level combinations or between two experimental conditions, and effects are confounded when an effect cannot be clearly attributed to one factor or interaction. In other words, experimental effects are confounded (aliased) if their calculated values can only be attributed to their combined influence on the response and not to their individual influences.

In fractional FD, the effects of interest should be unconfounded with other effects or confounded only with effects that negligibly affect the results. Prior to performing an experiment, researchers should know which effects are confounded.

Fractional factorial experiments are specified by first stating the defining contrast $I$. The defining contrast $I$ is the generator of this particular fraction [2].

For instance, to implement a three-level fractional factorial experiment with three factors- $A, B$ and $C$-it is necessary to designate the levels $x_{1}, x_{2}$, and $x_{3}$ of each factor $A, B$, and $C$, respectively, as 0,1 , or 2 , and to determine the defining contrast $I$. For instance, one could choose the defining contrast:

$$
I=A B^{2} C
$$

Then the experimenter can randomly select the fraction from the following options:

$$
\begin{aligned}
& x_{1}+2 x_{2}+x_{3}=0 \bmod (3) \\
& x_{1}+2 x_{2}+x_{3}=1 \bmod (3) \\
& x_{1}+2 x_{2}+x_{3}=2 \bmod (3)
\end{aligned}
$$


and perform the experiments which satisfy the chosen Eq. (7) regarding the levels $x_{1}, x_{2}$, and $x_{3}$ of parameters $A, B$, and $C$, respectively.

By applying the defining contrast, Eq. (6), the number of experiments decreases compared to full FD (shown by Eq. (5)):

$$
\text { number of experiments }=n^{k-1}
$$

Each additional defining contrast decreases the number of experiments in the same way:

$$
\text { number of experiments }=n^{k-m}
$$

where $m$ is the number of defining contrasts.

Full FD and fractional FD could be used to fit response surfaces. However, these designs are not rotatable. Rotatable designs estimate the response with equal precision at all points in the factor space that are equidistant from the center of the design [1]. In other words, a design is rotatable if the prediction variance depends only on the distance of the design point from the center of the design [8].

Rotatability is a desirable property for response surface models because, prior to collecting data and fitting the response surface, the orientation of the design with respect to the surface is unknown.

There are two designs that use the experimental units or test runs more efficiently than the three-level factorial experiments: the central composite design (CCD) and the Box-Behnken (BB) design. Both of these designs only require enough observations to estimate the second-order effects of the response surface, using three or five levels for each factor, rather than using all combinations of levels. Both of these designs are rotatable, at least approximately.

A CCD consists of a factorial design (the corners of a cube) together with center and star points [8], which allow for estimation of second-order effects. For a full quadratic model with $k$ factors, a CCD specifies $2^{k}+2 k+1$ design points. The type of CCD used (i.e., the position of the factorial and star points) depends on the number of factors and the desired properties of the design.

The basic central composite designs are:

- Circumscribed (CCC) with factor levels $(-\alpha,-1,0,1, \alpha)$

- Inscribed (CCI) with factor levels $(-1,-1 / \alpha, 0,1 / \alpha, 1)$

- Faced (CCF) with factor levels $(-1,0,1)$

In these designs, $\alpha$ is determined as follows [2]:

$$
\alpha=\sqrt[1 / 4]{2^{k}}
$$

A Box-Behnken design is rotatable and allows experimenters to work around extreme factor combinations. It does not contain an embedded factorial or fractional FD. A BB design requires $2 k(k-1)+1$ experiments, and the factors are examined at three levels $(-1,0,+1)$. Table 1 summarizes some important properties of designs used to fit response surfaces.

Table 1: Important properties of experiment designs

\begin{tabular}{|l|l|l|l|l|}
\hline Design & Factor levels & $\begin{array}{l}\text { Number of } \\
\text { experiments }\end{array}$ & Rotatable & Properties \\
\hline CCC & $-\alpha,-1,0,1, \alpha$ & & Yes & Good over entire design space \\
\cline { 1 - 2 } CCI & $-1,-1 / \alpha, 0,1 / \alpha, 1$ & \multirow{2}{*}{$2^{k}+2 k+1$} & No & $\begin{array}{l}\text { Good over central subset of design } \\
\text { space }\end{array}$ \\
\cline { 1 - 2 } CCF & $-1,0,1$ & & No & $\begin{array}{l}\text { Fair over entire design space, poor for } \\
\text { pure quadratic coefficients }\end{array}$ \\
\hline BB & $-1,0,1$ & $2 k(k-1)+1$ & Yes & $\begin{array}{l}\text { Like an inscribed CCD; however, } \\
\text { extremes are then poorly estimated }\end{array}$ \\
\hline
\end{tabular}




\section{USAGE OF EXPERIMENT DESIGN}

The factors supposed to be significant for a model of building air-tightness are the heat transfer coefficient for external walls $\left(x_{1}\right)$, heat transfer coefficient of the windows $\left(x_{2}\right)$, and position of housing units with respect to the building envelope $\left(x_{3}\right)[3]$. These factors are used in the experimental design.

Table 2 shows the variation of each factor. Thereby the lower and upper limits correspond to factor levels $\alpha$ and $\alpha$ for CCC only. For all other designs, the lower and upper limits correspond to factor levels -1 and 1 , respectively. All other factor levels used can be easily calculated using the defined upper and lower factor levels.

Table 2 Chosen factors and their limit values

\begin{tabular}{|c|c|}
\hline Factors & Limit values \\
\hline$x_{1}\left(\mathrm{~W} / \mathrm{m}^{2} \mathrm{~K}\right)$ & $0.45-1.25$ \\
\hline$\chi_{2}\left(\mathrm{~W} / \mathrm{m}^{2} \mathrm{~K}\right)$ & $0.7-3.5$ \\
\hline$x_{3}(\%)$ & $20-80$ \\
\hline
\end{tabular}

The Full FD requires many more experiments than the other designs, as shown in Table 3 , so it will not be chosen as the experiment design. Fractional FD, $\mathrm{CCl}$, and CCF will not be considered because they do not ensure the rotatability of the design, even though fractional FD is the least demanding design. Thus, the possible experiment designs are CCC and BB, as shown in Table 4.

Table 3 Number of experiments

\begin{tabular}{|l|l|l|l|l|l|l|}
\hline & Full FD & Fractional FD & CCC & CCI & CCF & BB \\
\hline Number of experiments & 27 & 9 & 15 & & 13 \\
\hline
\end{tabular}

Table 4 Plan of experiment defined by CCC and BB

\begin{tabular}{|c|c|c|c|c|c|c|}
\hline & \multicolumn{3}{|l|}{ CCC } & \multicolumn{3}{|l|}{ BB } \\
\hline No. & $x_{1}$ & $x_{2}$ & $x_{3}$ & $x_{1}$ & $x_{2}$ & $x_{3}$ \\
\hline 1 & 0.61 & 1.27 & 32.16 & 0.45 & 0.7 & 50 \\
\hline 2 & 0.61 & 1.27 & 67.84 & 0.45 & 3.5 & 50 \\
\hline 3 & 0.61 & 2.93 & 32.16 & 1.25 & 0.7 & 50 \\
\hline 4 & 0.61 & 2.93 & 67.84 & 1.25 & 3.5 & 50 \\
\hline 5 & 1.09 & 1.27 & 32.16 & 0.45 & 2.1 & 20 \\
\hline 6 & 1.09 & 1.27 & 67.84 & 0.45 & 2.1 & 80 \\
\hline 7 & 1.09 & 2.93 & 32.16 & 1.25 & 2.1 & 20 \\
\hline 8 & 1.09 & 2.93 & 67.84 & 1.25 & 2.1 & 80 \\
\hline 9 & 0.45 & 2.10 & 50.00 & 0.85 & 0.7 & 20 \\
\hline 10 & 1.25 & 2.10 & 50.00 & 0.85 & 0.7 & 80 \\
\hline 11 & 0.85 & 0.70 & 50.00 & 0.85 & 3.5 & 20 \\
\hline 12 & 0.85 & 3.50 & 50.00 & 0.85 & 3.5 & 80 \\
\hline 13 & 0.85 & 2.10 & 20.00 & 0.85 & 2.1 & 50 \\
\hline 14 & 0.85 & 2.10 & 80.00 & & & \\
\hline 15 & 0.85 & 2.10 & 50.00 & & & \\
\hline
\end{tabular}




\section{CONCLUSION}

In this paper, we presented the experimental designs used to model building air-tightness as second-order functions using the response surface method and corresponding experiment designs. The factors supposed as significant for a model of building air-tightness-and thus those used in the experiment designs-are the heat transfer coefficient for the external walls, the heat transfer coefficient of the windows, and the position of housing units with respect to the building envelope.

We compared the three-level full factorial and fractional factorial designs, central composite designs, and Box-Behnken design, and decided not to consider the full factorial design, fractional factorial design, and inscribed and faced central composite designs because they require many more experiments than the other designs and do not ensure design rotatability. We conclude that the Box-Behnken design and circumscribed central composite design are possible experiment designs, and future work will assess the experimental building air-tightness (Blower door tests) based on these designs. These experimental results will be used to obtain second-order model of building air-tightness that depend on chosen factors.

Previous work has shown that neural networks can be used to create a predictive model for measuring the air-tightness of residential units in local conditions, and that these networks show good response [9]. In further work, one could compare the results from a designed mathematical model and from predictive models based on a neural network with a database of measured air-tightness values of buildings in the field. The basic advantage of this type of prognostic model is the possibility of quickly assessing air-tightness without the need to conduct timeconsuming field measurements. The results obtained through the prognostic model can be applied in planning systematic energy refurbishment of residential buildings, improving energy efficiency and thermal comfort in accordance with EU recommendations.

\section{References:}

[1] Mason, R. L., Gunst, R. F., Hess, J. L., 2003: Statistical Design and Analysis of Experiments, John Wiley \& Sons, Inc.

[2] Montgomery, D.C., 2001: Analysis of Experiments, fifth edition, John Wiley \& Sons, Inc.

[3] Results of the project: Hungary-Croatia IPA Cross-border Co-operation Programme 2007-2013, Air tightness investigation of rooms from the point of view of energy and comfort.

[4] Berredo, R. C., Canha, L. N., Ekel, P. Ya., Ferreira, L. C. A., Maciel, M. V. C., 2008: Experimental Design and Models of Power System Optimization and Control, WSEAS Transactions on Systems and Control, Vol. 3, No. 1, pp. 40-49.

[5] Lazić, Lj., Mastorakis, N. E., 2010: Integrated Intelligent Modeling, Simulation and Design of Experiments for Software Testing Process, Latest Trends on Computers (Volume II),14th International Conference on Computers, pp. 555-567.

[6] Briano, E., Caballini, C., Giribone, P., Revetria, R., 2010: Design of Experiment and Montecarlo Simulation as Support for Gas Turbine Power Plant Availabilty Estimation, Proceedings of the 12th WSEAS International Conference on Automatic Control, Modelling \& Simulation, pp. 223-230.

[7] http://acad.depauw.edu/ harvey/ASDL2007/indextest.html, available online 16. June 2015.

[8] Product Help, Matlab, Version 7.7.0.471 (R2008b), September 17, 2008.

[9] Krstić, H., Koški, Ž., Ištoka Otković, I., Španić, M., 2014: Application of Neural Networks in Predicting Airtightness of Residential Units, Energy and Buildings, Vol. 84, pp. 160-168.,

doi:10.1016/i.enbuild.2014.08.007 